BNL 17056

Accelerator Department

CRISP $72-48$

BROOKHAVEN NATIONAL LABORATORY

ISABELLE PROJECT

Associated Universities, Inc.

Upt on, New York

INTERSECTING STORAGE ACCELERATOR NOTES

MAGNET TOLERANCES IN ISABELLE AND NONLINEAR RESONANCES

\author{
G. Parzen \\ July 26, 1972
}

NOTICE

This report was prepared as an account of work sponsored by the United States Government. Neither the United States nor the United States Atomic Energy Commission, nor any of their employees, nor any of their contractors, subcontractors, or their employees, makes any warranty, express or implied, or assumes any legal liability or responsibility for the accuracy, completeness or usefulness of any information, apparatus, product or process disclosed, or represents that its use would not infringe privately owned rights. 
Accelerator Department BROOKHAVEN NATIONAL LABORATORY Associated Universities, Inc. Upton, New York
CRISP 72-48

ISABELLE PROJECT

INTERSECTING STORAGE ACCELERATOR NOTES

MAGNET TOLERANCES IN ISABELLE AND NONL INEAR RESONANCES

$$
\begin{aligned}
\text { G. } & \text { Parzen } \\
\text { July } & 26,1972
\end{aligned}
$$

\begin{abstract}
There is reason to belleve that the nonlinear imperfection resonances, which are driven by random errors in the magnetic field, are likely to be considerably stronger in ISABELLE than they are in the ISR. This would require that ISABELLE should have a set of magnetic correction elements to control the harmonics which excite the relevant nonlinear imperfection resonances.
\end{abstract}

The summer study emphasized certain aspests of magnet tolerances in ISABELLE which require study and attention. Perhaps the most important aspect is that of the random errors in the magnetic field which are different from magnet to magnet and which generate the nonlinear imperfection resonances.

The ISR observes effects on the beam due to nonlinear imperfection resonances, including higher order resonances like the fifth order which are traditionally regarded as nonharmful. At the same time, the ISR working region is in the vicinity of several fifth order resonances (see Fig. 1) without apparent harm to the beam. Nevertheless, the nonlinear imperfection resonances up to some high order have to be regarded as potentially dangerous. The ISR experience can be interpreted as indicating that if the imperfection resonances were 5 to 10 times stronger, they might seriously hurt the beam.

ISABELLE and the ISR differ seriously in respect to the imperfection nonlinear resonances. There is reason to expect that in ISABELLE the imperfection resonances will be much stronger than in the ISR. This is because 
in the ISABELLE magnets, the field is determined by the position of the current blocks rather than the iron pole shape as in the ISR, and random errors in the current block positions will introduce random nonilnear terms in the field of each magnet, which drive the nonlinear imperfection resonances. In the ISR, it is difficult even to pin down the sources of random nonlinear field errors in the magnets, or to estimate them, but they should be relatively small.

The above remarks suggest strongly that ISABELLE should have a set of magnetic elements to control the harmonics which excite the relevant nonlinear imperfection resonances. It would also be useful to encourage CERN to measure the strength of the imperfection resonances present in the ISR, so that one can compare ISABELLE and the ISR in this respect.

\section{Systematic Errors}

Regarding the systematic errors in the magnets, errors which are the same from magnet to magnet, the problems seem less severe. These errors may be due to saturation effects, magnetization effects, end effects, etc. They can be compensated for by having separately excited multipole windings in the magnets.

The ISR magnets each have 12 pole-face windings with separate power supplies, and in addition the pole-face windings in $F$ and $D$ magnets can be separate1y excited. If ISABELLE magnets have something similar then one could control a11 multipoles up to $b_{24}$.

One systematic nonlinearity deserves further consideration. This is the deliberate sextupole term $b_{2}$ which is introduced to make dv/dp almost zero. The $b_{2}$ required is considerably higher than the similar $b_{2}$ required in the ISR, and the ISABELLE symnetry allows more azimuthal harmonics to be present which can excite essential or structure nonlinear resonances close to the ISABELLE working region (see Fig. 1).

Distr.: HE S\&P at Physics

$S \& P$ at $A D$

Outside Users

M. Goldhaber, L.J. Haworth, G.H. Vineyard 
Figure 1. ISABELLE $\vee$ Diagram.

Heavy lines are structure resonances.

Light lines are imperfection resonances. The order of the resonance is given by the numbered intersection point through which it passes.

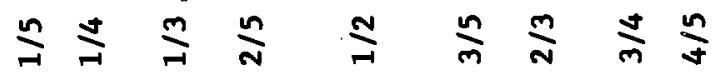

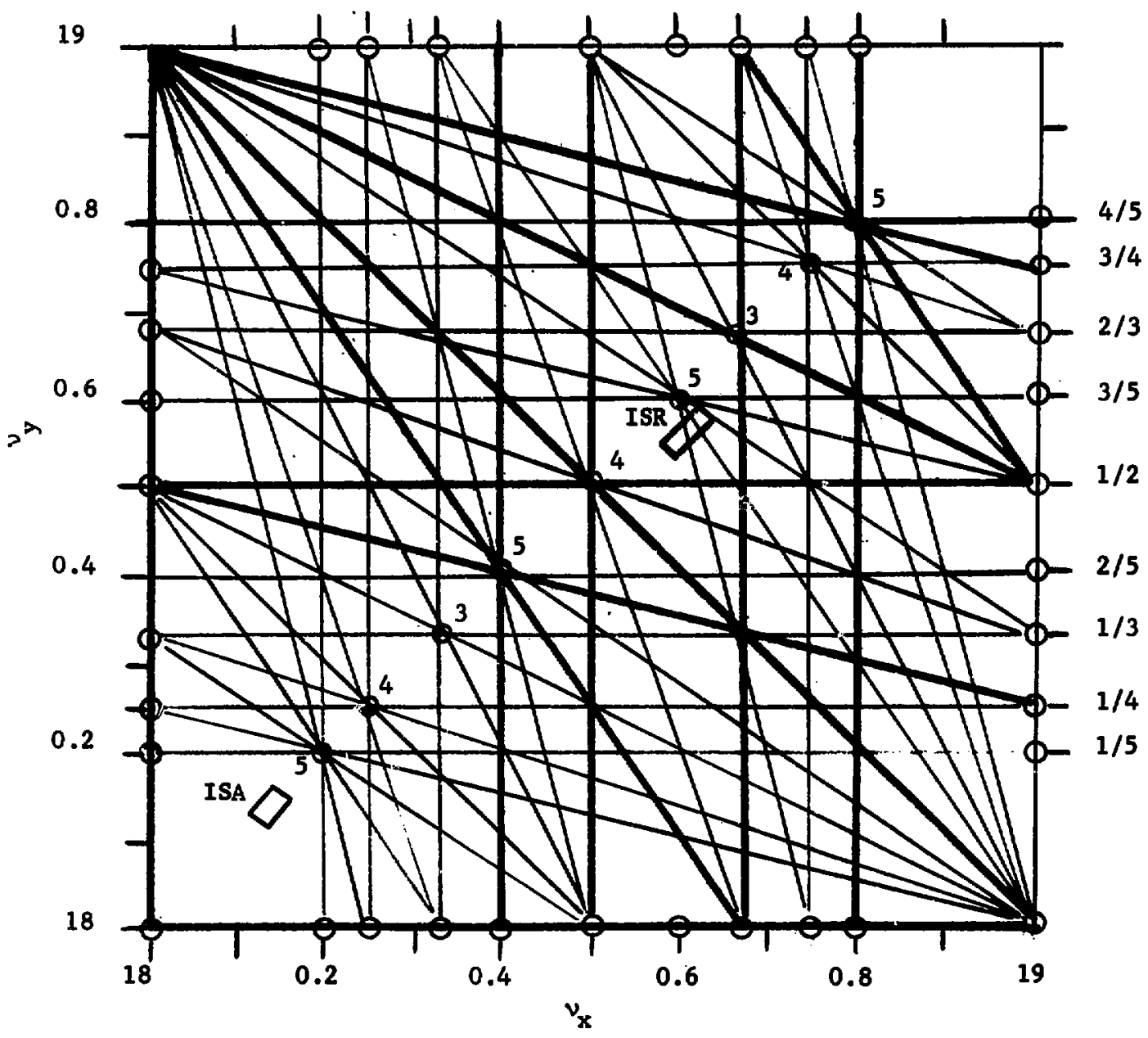

